\title{
Penetrating Facial Injury
}

\author{
Siddharth P. Dubhashi • Kaushal Choudhary
}

Received: 7 August 2013 / Accepted: 14 August 2013 / Published online: 27 August 2013

(C) Association of Surgeons of India 2013

\begin{abstract}
Penetrating facial trauma presents a wide spectrum of injuries and management dilemmas, due to the potential injuries that may occur during removal of the retained objects. This is a report of a 3-year-old child who presented with a penetrating facial injury due to a screwdriver. Proper examination, radiological evaluation and early decision-making with a multidisciplinary approach provide an optimal treatment outcome in such cases.
\end{abstract}

Keywords Facial trauma $\cdot$ Screwdriver $\cdot$ Multidisciplinary

Penetrating head injuries caused by pointed objects account for about $0.4 \%$ of all head injuries [1]. Penetrating facial trauma presents a wide spectrum of injuries and management dilemmas, due to the potential injuries that may occur during removal of the retained objects [2].

A 3-year-old male child was brought to the emergency room by his parents due to a penetrating injury through his right maxilla by a screwdriver. The screwdriver was lodged $4 \mathrm{~cm}$ below the right eye and was fixed into the maxillary bone (Fig. 1). Active bleeding was seen from the right nostril. X-ray skull showed the screwdriver penetrating the maxilla and reaching the orbital margin (Fig. 2). The child was posted for emergency removal of the foreign body under general

\section{S. P. Dubhashi $\cdot$ K. Choudhary}

Department of Surgery, Padmashree Dr. D. Y. Patil Medical College, Hospital and Research Centre, Dr. D. Y. Patil Vidyapeeth,

Pimpri-Chinchwad, Pune, India

\section{S. P. Dubhashi $(\varangle)$}

A2/103, Shivranjan Towers, Someshwarwadi, Pashan, Pune 411008, Maharashtra, India

e-mail: spdubhashi@gmail.com

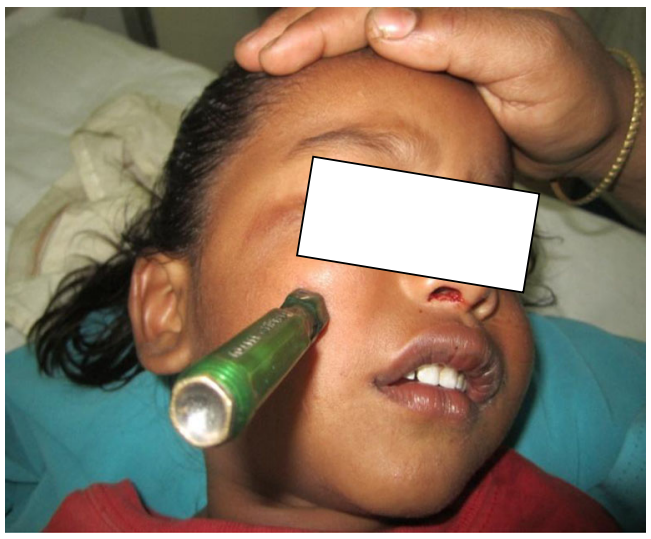

Fig. 1 Penetrating screwdriver injury

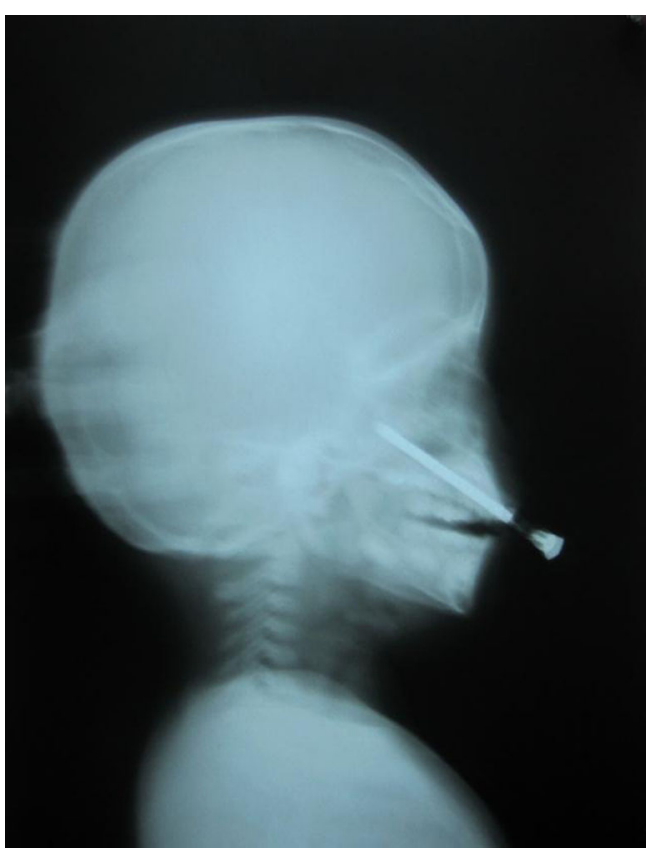

Fig. 2 Skull radiograph (lateral view) 
anaesthesia. The screwdriver was removed with gradual continuous rotatory movements.

Screwdrivers, when used by children as toy objects, pose serious life-threatening problems, due to risk of penetrating injuries. The concentration of force into the small area at the tip of these rigid tools may enable penetration into the skull bones. Once through the bone, the shaft of the screwdriver may then pivot around the entry point in the skull [3]. In case of maxillofacial injuries, immediate attention needs to be directed towards evaluating and managing the airway and bleeding. Blunt objects with irregular tips, which can introduce foreign material in situations where the penetrating object is contaminated, carry a huge potential for soft tissue infections [4]. Proper examination, radiological evaluation and early decision-making with a multidisciplinary approach provide an optimal treatment outcome in such cases.

\section{References}

1. Ishikawa E, Meguro K, Yonaka K, Murakami T, Narashima K, Aoki T, Nose T (2000) Intracerebellar penetrating injury and abscess due to a wooden foreign body. Neurol Med Chir 40:458-462

2. Khalil N, Elmany MN, Miller JD (1991) Transcranial stab wounds: morbidity and medicolegal awareness. Surg Neurol 35(4):294-299

3. Tutton MG, Chitnavis B, Stell IM (2000) Screwdriver assaults and intracranial injuries. J Accid Emerg Med 17:225-226

4. Peterson K, Waterman P (2011) Prophylaxis and treatment of infections associated with penetrating traumatic injury. Expert Rev Anti Infect Ther 9:81-96 